\title{
Clinical Characteristics and Treatment Outcome of Peginterferon Plus Ribavirin in Patients Infected with Genotype 6 Hepatitis C Virus in Korea: A Multicenter Study
}

\begin{abstract}
Su Rin Shin ${ }^{1,2}$, Young Seok Kim³ ${ }^{3}$, Young-Seok Lim ${ }^{4}$, June Sung Lee ${ }^{5}$, Jin Woo Lee ${ }^{6}$, Sun Myung Kim ${ }^{7}$ Sook-Hyang Jeong ${ }^{8}$, Joo Hyun Sohn ${ }^{9}$, Myung Seok Lee ${ }^{10}$, and Sang Hoon Park ${ }^{10}$

${ }^{1}$ Health Care Center, Samsung Changwon Hospital, Sungkyunkwan University School of Medicine, Changwon, ${ }^{2}$ Department of Internal Medicine, Kangwon National University College of Medicine, Chuncheon, ${ }^{3}$ Department of Internal Medicine, Soonchunhyang University College of Medicine, Bucheon, ${ }^{4}$ Department of Internal Medicine, Asan Medical Center, University of Ulsan College of Medicine, Seoul, ${ }^{5}$ Department of Internal Medicine, Inje University Ilsan Paik Hospital, Inje University College of Medicine, Goyang, ${ }^{6}$ Department of Internal Medicine, Inha University School of Medicine, Incheon, ${ }^{7}$ Department of Internal Medicine, Gimpo Woori Hospital, Gimpo, ${ }^{8}$ Department of Internal Medicine, Seoul National University Bundang Hospital, Seongnam, ${ }^{9}$ Department of Internal Medicine, Hanyang University Guri Hospital, Hanyang University College of Medicine, Guri, and ${ }^{10}$ Department of Internal Medicine, Hallym University Kangnam Sacred Heart Hospital, Seoul, Korea
\end{abstract}

Background/Aims: Because of the limited geographic distribution, there have been insufficient data regarding hepatitis $\mathrm{C}$ virus (HCV) genotype 6 in Korea. This study aimed to investigate the clinical characteristics and available treatment outcomes of patients with genotype $6 \mathrm{HCV}$ in Korea. Methods: From 2004 to 2014, data were collected from Korean patients infected with genotype $6 \mathrm{HCV}$ in eight hospitals. Results: Thirty-two patients had genotype $6 \mathrm{HCV}$. The median age was 44 years, and $6 \mathrm{c}$ was the most common subtype. The baseline median alanine transaminase level was 88 (21 to 1,019) IU/mL, and the HCV RNA level was $1,405,000(96,500$ to $28,844,529) \mathrm{IU} / \mathrm{mL}$. Twenty-five patients were treated with peginterferon (PEG-IFN) and ribavirin. Three follow-up losses occurred. Additionally, 13 patients attained a sustained virologic response (SVR), seven patients relapsed, and two patients exhibited a null response. The SVR rates were $40 \%$ and $75 \%$ for the 24 - and more than 48 week treatments, respectively, and five of the six patients who achieved a rapid virologic response (RVR) attained a SVR. Conclusions: Korean patients infected with genotype $6 \mathrm{HCV}$ are relatively young, and $6 \mathrm{c}$ is the most common subtype. When treated with PEG-IFN and ribavirin, the SVR rate was $52 \%$. Similar to other genotypes, a longer duration of treatment and attainment of RVR are important for SVR. (Gut Liver 2017;11:270-275)

Key Words: Hepatitis C, chronic; Genotype 6; Peginterferon alfa; Ribavirin

\section{INTRODUCTION}

Hepatitis $\mathrm{C}$ virus (HCV) is a major leading cause of chronic liver disease including cirrhosis and hepatocellular carcinoma and about 130 to 150 million people globally have chronic hepatitis C (CHC) infection. ${ }^{1,2}$ According to the sequencing of HCV isolate, there are seven genotypes and 67 subtypes. ${ }^{3}$ While genotype 1, 2, and 3 are more prevalent and found around the world-wide, genotype 4, 5 and 6 are distributed in limited area. Genotype 4 and 5 are mainly distributed in the Middle East and Africa, and 6 in the Southern China and Southeast Asia including Singapore, Laos, Thailand, Vietnam, and Myanmar, where comprises up to $50 \%$ of all hepatitis C patients. On the other hand, HCV genotype 6 is rare in Korea where its prevalence is known as about $1 \%$. $^{4,5}$

Since new oral direct-acting-agents (DAA) have been introduced, a treatment paradigm for HCV infection is changing. However, although some clinical trials demonstrated higher sustained virologic response (SVR) achievement in genotype 6 patients using DAA, those data included only small number of patients with genotype $6{ }^{6,7}$ Moreover, DAA-based regimen is not likely to be available in many countries yet because of countries' or personal socio-economic situations. For these reasons, peginterferon (PEG-IFN) and ribavirin are still affordable treatment regimens in real-world setting.

\footnotetext{
Correspondence to: Sang Hoon Park

Division of Gastroenterology and Hepatology, Department of Internal Medicine, Hallym University Kangnam Sacred Heart Hospital, 1 Singil-ro, Yeongdeungpo-gu, Seoul 07441, Korea

Tel: +82-2-829-5121, Fax: +82-2-846-4669, E-mail: sanghoon@hallym.or.kr

Received on March 24, 2016. Revised on May 12, 2016. Accepted on May 12, 2016. Published online October 13, 2016 pISSN 1976-2283 eISSN 2005-1212 https://doi.org/10.5009/gnl16163

@ This is an Open Access article distributed under the terms of the Creative Commons Attribution Non-Commercial License (http://creativecommons.org/licenses/by-nc/4.0) which permits unrestricted non-commercial use, distribution, and reproduction in any medium, provided the original work is properly cited.
} 
This study was conducted to find the clinical characteristics and treatment outcomes in the patients infected with HCV genotype 6 in Korea.

\section{MATERIALS AND METHODS}

From April 2004 to December 2014, data of patients infected with genotype 6 were reviewed from one regional hospital and seven hospitals affiliated with medical colleges located in Gyeonggi-Incheon region, South Korea. Among them, seven patients were from the Gyeonggi-Incheon Peginterferon Alpha and Ribavirin Effect in CHC Treatment (KIPECT) study group. ${ }^{8}$

Baseline clinical and virologic characteristics were obtained by retrospective review of medical records. Data collection was performed with an Excel (Microsoft Corp., Redmond, WA, USA)based case report form by physicians at each individual hospital. The study protocol was approved by the Institutional Review Boards for exemption from the requirement for informed consent at each hospital and was conducted in accordance with the principles of the Declaration of Helsinki.

All patients were Koreans and anti-HCV positive more than 6 months or clinically assessed as a CHC by using laboratory and radiologic findings. HCV genotyping was conducted by the reverse hybridization principle, nested polymerase chain reaction (PCR) was performed with biotinylated primers from the $5^{\prime}$ untranslated region, and the second-round product was genotyped with a second-generation line probe assay (INNOLiPA HCV II; Innogenetics, Ghent, Belgium) or restriction fragment mass polymorphism (RFMP; Genematrix Inc., Seongnam, Korea), or direct sequencing method as used in each institution. Qualitative HCV RNA, when it performed, was conducted by an RNA PCR and hybrid method, Cobas Amplicor HCV test version 2.0 (Roche Molecular Systems, Branchburg, NJ, USA; detection limit, $50 \mathrm{IU} / \mathrm{mL}$ ). Quantitative HCV RNA was measured by realtime PCR assay using the Abbott RealTime HCV assay (Abbott Molecular, Des Plaines, IL, USA; lower detection limit $12 \mathrm{IU} / \mathrm{mL}$ ) or CobasAmpliPrep/CobasTaqMan HCV assay (Roche Molecular Systems, Pleasanton, CA, USA; lower detection limit $15 \mathrm{IU} / \mathrm{mL}$ ).

When the patients were treated, either PEG-IFN $\alpha$-2a or PEGIFN $\alpha-2 b$ plus ribavirin were used. The starting dosage and dose modification of PEG-IFN and ribavirin were determined based on the current guidelines suggested by the Korean Association for the Study of the Liver. However, according to the nature of this retrospective study, selection and discontinuation as well as dosing and treatment duration of PEG-IFN and ribavirin were not controlled, but reflected the clinical practice of the attending physicians.

The patients who developed anemia, neutropenia, and/or thrombocytopenia were generally managed with a dose reduction or permanent discontinuation of the PEG-IFN or ribavirin, as per the guidelines provided.

A rapid virological response (RVR) was defined as undetect- able serum HCV-RNA at week 4. The complete early virologic response (cEVR) is based on week 12 data and is defined as an undetectable HCV RNA. A partial EVR (pEVR) refers to a $2 \log _{10}$ or greater decrease from baseline in HCV RNA at week 12, but persistent detectable HCV RNA. End of treatment response (ETR) was defined as undetectable HCV RNA at the end point of treatment. A SVR was defined as undetectable HCV RNA 24 weeks after completion of antiviral therapy maintained throughout the remaining documented follow-up period. Virological relapse was defined as achieving an ETR but subsequently becoming HCV RNA positive after cessation of treatment. An adherence to antiviral therapy was defined as the actual dose administered divided by the total dose first expected.

Comparison of treatment outcome according to the presence of RVR and the treatment duration was performed using twosided Fisher exact test.

\section{RESULTS}

A total of 32 patients were enrolled. Included patients were aged between 34 and 57 (median, 44) years, and 63\% were male. No specific risk for $\mathrm{CHC}$ was identified but two patients who received tattooing from the same unlicensed person. Three patients showed hepatitis B surface antigen (HBsAg) positive but negative HBV DNA on their serum (Table 1).

Most common subtype was $6 \mathrm{c}$, documented in 26 patients $(81 \%)$. There were $6 \mathrm{a}$ in three patients, mixed 6/6c in two patients, and 6 in one patient, respectively. Baseline median aspartate transaminase level was 80 (24 to 1,123$) \mathrm{U} / \mathrm{L}$ and alanine transaminase level was 88 (21 to 1,019) U/L, and HCV RNA level was $1,405,000(96,500$ to $28,844,529) \mathrm{IU} / \mathrm{mL}$. Based on laboratory and imaging findings, five patients showed clinical features suggestive liver fibrosis.

Twenty-five treatment-naïve patients were treated with 180 $\mu \mathrm{g}$ of PEG-IFN $\alpha$-2a or 1.0 to $1.5 \mu \mathrm{g} / \mathrm{kg}$ of PEG-IFN $\alpha-2 \mathrm{~b}$ with 800 to $1,200 \mathrm{mg}$ of ribavirin. Treatment duration was determined by physicians' discretion, and intended treatment duration was ranged 24 to 54 weeks (Table 2).

Overall, SVR was attained in 13 patients (52\%). As follow-up loss occurred in three patients, a total of 22 patients conformed to the treatment protocol. Seven patients relapsed and two were null-responders including one who discontinued treatment for no early virologic response.

By treatment durations, four of 10 patients attained SVR following 24 weeks and nine of 12 patients following more than 48 weeks treatment. When excluding three patients who lost follow-up, the treatment outcome was slightly improved according to longer duration of treatment $(\mathrm{p}=0.192)$.

RVR was checked in 14 patients. Five of six patients who showed positive RVR had attained SVR whereas four of eight patients without RVR attained SVR. Two patients who did not achieve EVR were nonresponder. In three patients with pEVR, 
Table 1. Clinical Characteristics of Patients with Chronic Hepatitis C Genotype 6

\begin{tabular}{|c|c|c|c|c|c|c|c|c|c|c|c|c|}
\hline No. & Sex/age & $\begin{array}{l}\text { Genotyping } \\
\text { method }\end{array}$ & Subtype & $\begin{array}{c}\text { Baseline HCV } \\
\text { RNA, IU/mL }\end{array}$ & $\begin{array}{c}\text { AST, } \\
\text { U/L }\end{array}$ & $\begin{array}{l}\text { ALT, } \\
\text { U/L }\end{array}$ & $\begin{array}{c}\text { WBC, } \\
/ \mu \mathrm{L}\end{array}$ & $\begin{array}{l}\mathrm{Hb}, \\
\mathrm{g} / \mathrm{dL}\end{array}$ & $\begin{array}{c}\text { Platelets, } \\
\times 10^{3} / \mu \mathrm{L}\end{array}$ & $\begin{array}{c}\text { Alcohol*, } \\
\text { g/day }\end{array}$ & Remark & US \\
\hline 1 & $\mathrm{M} / 45$ & INNO-LiPA & $6 a$ & $3,948,730$ & 57 & 67 & 5,780 & 16.5 & 167 & 10 & - & - \\
\hline 2 & $\mathrm{M} / 53$ & INNO-LiPA & $6 c$ & Positive & 122 & 28 & 5,430 & 14.0 & 54 & Nil & - & - \\
\hline 3 & $\mathrm{M} / 46$ & RFMP & $6 a$ & $1,670,000$ & 121 & 181 & 4,350 & 15.7 & 124 & Nil & - & - \\
\hline 4 & $\mathrm{~F} / 39$ & RFMP & $6 a$ & 185,040 & 46 & 108 & 5,720 & 16.0 & 126 & 60 & - & - \\
\hline 5 & $\mathrm{M} / 54$ & RFMP & $6 c$ & 283,400 & 97 & 78 & 3,260 & 14.0 & 156 & Nil & Diabetes & - \\
\hline 6 & $\mathrm{M} / 37$ & RFMP & $6 c$ & $7,560,000$ & 78 & 154 & 5,840 & 15.9 & 224 & 25 & - & - \\
\hline 7 & $\mathrm{M} / 35$ & RFMP & $6 c$ & $5,170,000$ & 224 & 236 & 4,970 & 15.6 & 95 & 25 & Diabetes & CLD \\
\hline 8 & $\mathrm{M} / 45$ & RFMP & $6 c$ & 789,285 & 71 & 117 & 7,400 & 15.2 & 110 & Nil & - & - \\
\hline 9 & $\mathrm{M} / 36$ & RFMP & $6 c$ & $28,844,529$ & 55 & 85 & 5,900 & 15.0 & 201 & Nil & - & - \\
\hline 10 & $\mathrm{M} / 48$ & RFMP & $6 c$ & 356,089 & 87 & 47 & 3,900 & 16.4 & 33 & 10 & Diabetes & $\mathrm{LC}$ \\
\hline 11 & $\mathrm{~F} / 45$ & RFMP & $6 c$ & Positive & 72 & 91 & 6,900 & 13.1 & 195 & Nil & - & CLD \\
\hline 12 & $\mathrm{~F} / 50$ & Direct sequencing & $6 c$ & $10,266,000$ & 25 & 33 & 6,000 & 13.2 & 247 & Nil & - & - \\
\hline 13 & $\mathrm{~F} / 40$ & RFMP & $6 c$ & $1,260,000$ & 157 & 189 & 6,000 & 14.9 & 186 & Nil & - & CLD \\
\hline 14 & $\mathrm{M} / 40$ & RFMP & 6 & $1,650,000$ & 38 & 56 & 5,100 & 15.6 & 147 & Nil & - & - \\
\hline 15 & $\mathrm{M} / 41$ & RFMP & $6 c$ & $9,330,000$ & 43 & 21 & 7,300 & 16.8 & 162 & 30 & $\mathrm{HBsAg}+$ & - \\
\hline 16 & $\mathrm{~F} / 39$ & RFMP & $6 a / c$ & $1,127,568$ & 127 & 46 & 4,360 & 12.3 & 132 & Nil & - & - \\
\hline 17 & $\mathrm{~F} / 36$ & RFMP & $6 c$ & $13,068,693$ & 50 & 71 & 4,790 & 13.8 & 174 & 60 & - & - \\
\hline 18 & $\mathrm{M} / 43$ & RFMP & $6 c$ & $1,260,000$ & 157 & 189 & 5,500 & 14.9 & 186 & Nil & Diabetes & - \\
\hline 19 & $\mathrm{~F} / 43$ & RFMP & $6 / 6 c$ & $4,980,000$ & 96 & 140 & 5,700 & 15.7 & 238 & Nil & HBsAg+ & - \\
\hline 20 & $\mathrm{M} / 54$ & Direct sequencing & $6 c$ & 131,000 & 183 & 373 & 4,200 & 13.7 & 176 & Nil & - & - \\
\hline 21 & $\mathrm{M} / 47$ & RFMP & $6 c$ & $9,040,000$ & 34 & 63 & 5,800 & 14.3 & 279 & Nil & - & - \\
\hline 22 & $\mathrm{~F} / 56$ & RFMP & $6 c$ & $1,390,000$ & 88 & 136 & 5,300 & 13.1 & 165 & Nil & - & - \\
\hline 23 & $\mathrm{~F} / 57$ & RFMP & $6 c$ & 459,000 & 45 & 29 & 3,600 & 13.2 & 155 & Nil & - & - \\
\hline 24 & $\mathrm{M} / 44$ & RFMP & $6 c$ & $2,720,000$ & 102 & 190 & 5,200 & 15.1 & 177 & 20 & - & - \\
\hline 25 & $\mathrm{M} / 49$ & RFMP & $6 c$ & 975,000 & 100 & 64 & 4,700 & 15.2 & 54 & Nil & - & $\mathrm{LC}$ \\
\hline 26 & $\mathrm{M} / 49$ & RFMP & $6 c$ & 96,500 & 151 & 479 & 5,300 & 16.9 & 233 & Nil & - & - \\
\hline 27 & $\mathrm{M} / 40$ & RFMP & $6 c$ & $1,420,000$ & 56 & 67 & 8,400 & 16.4 & 136 & 10 & HBsAg+ & - \\
\hline 28 & $\mathrm{M} / 50$ & RFMP & $6 c$ & 637,000 & 82 & 173 & 5,800 & 15.7 & 122 & Nil & - & - \\
\hline 29 & $\mathrm{M} / 34$ & RFMP & $6 c$ & $1,270,000$ & 139 & 350 & 4,900 & 16.9 & 243 & 20 & - & - \\
\hline 30 & $\mathrm{~F} / 38$ & RFMP & $6 c$ & $7,000,000$ & 54 & 33 & 5,500 & 13.5 & 191 & Nil & - & - \\
\hline 31 & $\mathrm{M} / 37$ & RFMP & $6 c$ & 609,300 & 1,123 & 1,019 & 4,560 & 16.1 & 103 & 40 & - & - \\
\hline 32 & $\mathrm{~F} / 39$ & RFMP & $6 c$ & $9,106,107$ & 24 & 24 & 5,640 & 13.1 & 178 & Nil & - & - \\
\hline
\end{tabular}

HCV, hepatitis C virus; AST, aspartate transferase; ALT, alanine transferase; WBC, white blood cell; Hb, hemoglobin; US, ultrasonography; M, male; INNO-LiPA, line probe assay; RFMP, restriction fragment mass polymorphism; F, female; CLD, chronic liver disease; LC, liver cirrhosis; HBsAg+, hepatitis B surface antigen positive.

*Estimated amount.

two were relapsed and one attained SVR ( $p=0.301)$.

Most common adverse event was flu-like syndrome, and dose reduction was necessary in $24 \%$ (6/25) of patients. There was no treatment discontinuation by adverse events.

\section{DISCUSSION}

HCV genotype 6 is geographically restricted in South East Asia and surrounding regions, where $30 \%$ to 50\% of all hepati- tis $C$ patients are infected with genotype $6 .^{9-11}$ Diverse subtypes of genotype 6 are accumulated and newly isolated subtypes are almost always reported in this area. So, it is suggested that genotype 6 may have been long circulated or evolved within Southeast Asia, and transmitted to the adjacent countries. ${ }^{12}$ Whereas most data about genotype $6 \mathrm{HCV}$ were centered on these regions, there have been not many data in Korea probably due to low prevalence of HCV genotype 6 . While Shin et al. ${ }^{13}$ recently reported the prevalence of genotype 6 as 10.5\%, most 
Table 2. Treatment Profile of Patients with Genotype 6 Who Received Peginterferon and Ribavirin

\begin{tabular}{|c|c|c|c|c|c|c|c|c|c|}
\hline No. & PEG-IFN & $\begin{array}{l}\text { Initial ribavirin } \\
\text { dose, } \mathrm{mg}\end{array}$ & $\begin{array}{c}\text { PEG-IFN } \\
\text { adherence, \% }\end{array}$ & $\begin{array}{c}\text { Ribavirin } \\
\text { adherence, \% }\end{array}$ & $\begin{array}{c}\text { Intended treatment } \\
\text { duration }\end{array}$ & RVR & EVR & ETR & SVR \\
\hline 1 & $2 a$ & 800 & 100 & 100 & 24 & - & cEVR & Yes & Relapse \\
\hline 2 & $2 a$ & 600 & 100 & 100 & 24 & No & No & - & Nonresponder \\
\hline 3 & $2 \mathrm{a}$ & 1,000 & 100 & 100 & 48 & - & pEVR & Yes & Relapse \\
\hline 4 & $2 \mathrm{a}$ & 1,000 & 100 & 100 & 48 & Yes & cEVR & Yes & Yes \\
\hline 5 & $2 \mathrm{a}$ & 1,000 & 79 & 83 & 48 & Yes & cEVR & Yes & Yes \\
\hline 6 & $2 a$ & 1,000 & 93 & 95 & 48 & - & pEVR & Yes & Yes \\
\hline 8 & $2 \mathrm{a}$ & 900 & 100 & 100 & 24 & - & cEVR & Yes & Yes \\
\hline 9 & $2 b$ & 1,200 & 100 & 100 & 48 & No & No & No & Nonresponder \\
\hline 10 & $2 b$ & 800 & 100 & 100 & 24 & - & cEVR & Yes & Relapse \\
\hline 11 & $2 b$ & 1,000 & 100 & 100 & 24 & - & cEVR & Yes & Relapse \\
\hline 12 & $2 a$ & 1,000 & 100 & 100 & 24 & No & pEVR & Yes & Relapse \\
\hline 13 & $2 a$ & 1,000 & 100 & 100 & 16 & - & cEVR & - & F/U loss \\
\hline 14 & $2 a$ & 1,000 & 100 & 100 & 13 & - & cEVR & - & F/U loss \\
\hline 15 & $2 b$ & 1,000 & 100 & 100 & 48 & No & cEVR & Yes & Yes \\
\hline 16 & $2 b$ & 1,000 & 84 & 82 & 54 & Yes & cEVR & Yes & Yes \\
\hline 17 & $2 a$ & 800 & 98 & 100 & 48 & No & cEVR & Yes & Yes \\
\hline 18 & $2 \mathrm{a}$ & 1,000 & 100 & 82 & 48 & - & cEVR & Yes & Yes \\
\hline 19 & $2 a$ & 1,000 & 100 & 100 & 48 & - & cEVR & Yes & Yes \\
\hline 20 & $2 a$ & 1,000 & 100 & 100 & 24 & Yes & cEVR & Yes & Yes \\
\hline 21 & $2 b$ & 800 & 100 & 100 & 24 & No & cEVR & Yes & Yes \\
\hline 22 & $2 b$ & 800 & 100 & 100 & 48 & - & cEVR & Yes & Relapse \\
\hline 23 & $2 b$ & 800 & 100 & 75 & 24 & Yes & cEVR & Yes & Relapse \\
\hline 28 & $2 b$ & 1,000 & 100 & 100 & 24 & No & cEVR & Yes & Yes \\
\hline 29 & $2 b$ & 1,000 & 100 & 100 & 48 & Yes & cEVR & Yes & Yes \\
\hline 32 & $2 b$ & 800 & 100 & 100 & 20 & No & cEVR & - & $\mathrm{F} / \mathrm{U}$ loss \\
\hline
\end{tabular}

PEG-IFN, peginterferon; RVR, rapid virologic response; EVR, early virologic response; ETR, end of treatment response; SVR, sustained virologic response; cEVR, complete early virologic response; $p E V R$, partial early virologic response; $F / U$, follow up.

other studies reported the prevalence as about $1.0 \% .^{8,13-15}$ The affiliated hospital of Shin et al. ${ }^{13}$ is located where many immigrants from Southeast Asia and China and drug abusers exist, which may explain the higher prevalence than others.

Genotype $6 \mathrm{HCV}$ is highly diverse with 23 subtypes and certain subtypes have different geographic predominance like genotypes; 6a in South China, Taiwan, and Hong Kong, 6n in Myanmar, 6f in Thailand, and 6g in Indodesia. ${ }^{1,16}$ Until recently, subtype $6 \mathrm{c}$ is an overwhelming subtype regardless of genotyping methods in Korea. ${ }^{13-15}$ Interestingly, clustered $6 c$ has not been reported but in Korea since first isolated as a sole strain from a commercial blood donor in Thailand. ${ }^{17}$ We assume that 6c is a rare HCV variant and its spread within Korea might be related with migration of some hosts.

In this study, RFMP was most commonly used, that is known as accurate for HCV genotyping. On the other hand, INNO-LiPA HCV II (Innogenetics) has been criticized due to less complete ability to distinguish genotype 6 from 1, especially 6a from 1b. ${ }^{15,18-21}$ Although a gold standard for genotyping and subtyping is direct sequencing assay, RFMP assay could distinguish mass differences between oligonucleotide fragment levels and be most reliable modality among commercial kits. We also suggest that further study is required to investigate the prevalence and distribution of each subtypes of genotype 6 with direct sequencing or combining two or more modalities.

To date, virological and clinical features of hepatitis $C$ genotype 6 are known to be not significantly different to genotype 1, and 2/3. ${ }^{1,16,22}$ However, Korean patients infected with genotype 6 tend to be younger and have chronic hepatitis rather than advanced stage such as hepatocellular carcinoma or cirrhosis. ${ }^{11,23}$ These suggest that it has been not so long since a transmission into Korea and propagation of HCV genotype 6 occurred. We would prevent further amplification of genotype 6 infection in Korea by tracking human migration and transmission route of genotype $6 \mathrm{HCV}$.

Genotype is an important factor of response to treatment. 
Prior studies have suggested that the HCV genotype 6 has responded to the IFN-based treatment better than genotype 1 but less than genotype $2 / 3$. The 48 -week treatment may be more effective to achieve SVR than 24-week treatment in PEG-IFN and ribavirin combination. Those who achieve RVR may receive the shorter 24-week treatment. ${ }^{23-27}$ Despite statistically insignificant with too small sample size, our results showed a similar trend to the prior data. In our study, SVR rates were $40 \%$ and $75 \%$ according to the 24- and more than 48-week of PEG-IFN and ribavirin treatment respectively and RVR showed high positive predictive value (83\%).

Since the introduction of DAA, a treatment paradigm for $\mathrm{CHC}$ has been rapidly changing. Combination of PEG-IFN and ribavirin is not recommended as a standard treatment of genotype 1 anymore and plays a minimal role even in genotype 2/3. , 28,29 $^{5}$ However, unlike the major genotypes of HCV infection, data about minor genotypes such as genotype 6 are still limited. ${ }^{6,30}$ In addition, a surpassing cost per SVR of DAA is a major hurdle in the real world. ${ }^{31,32}$ Considering that a compulsory public health care system exists in Korea, where the lowest cost per cure is a more valuable, PEG-IFN and ribavirin could not be discarded yet. Therefore, we consider the results of our study are still meaningful for guide to treat patients infected with genotype 6 $\mathrm{HCV}$.

This is a retrospective study. Nevertheless, a prospective study about genotype $6 \mathrm{HCV}$ is hardly to be established due to low prevalence. To overcome inhomogeneity of enrolled patients and treatment regimen, the subjects were limited as Koreans.

In this study, we showed that Korean patients infected genotype $6 \mathrm{HCV}$ tended to be younger and have relatively short infection duration comparing to those who in the prevalent area. In Korea, $6 c$ is the most common subtype. When treated with PEG-IFN and ribavirin combination, the overall SVR rate was observed as 52\% (13/25) in patients. As like other HCV infection, longer duration of treatment and attainment of RVR are favorable to achieve SVR in genotype $6 \mathrm{HCV}$ infection. Although the treatment profile of our study is not an updated one, we believe that this is valuable data to have insights regarding the evolution and spread of genotype 6 HCV in Korea and manage patients infected with genotype $6 \mathrm{HCV}$.

\section{CONFLICTS OF INTEREST}

No potential conflict of interest relevant to this article was reported.

\section{REFERENCES}

1. Chao DT, Abe K, Nguyen MH. Systematic review: epidemiology of hepatitis C genotype 6 and its management. Aliment Pharmacol Ther 2011;34:286-296.

2. World Health Organization. Guidelines for the screening, care and treatment of persons with hepatitis C infection. Geneva: World Health Organization, 2014.

3. Smith DB, Bukh J, Kuiken C, et al. Expanded classification of hepatitis $\mathrm{C}$ virus into 7 genotypes and 67 subtypes: updated criteria and genotype assignment web resource. Hepatology 2014;59:318327

4. Gower E, Estes C, Blach S, Razavi-Shearer K, Razavi H. Global epidemiology and genotype distribution of the hepatitis $\mathrm{C}$ virus infection. J Hepatol 2014;61(1 Suppl):S45-S57.

5. Korean Association for the Study of the Liver (KASL). KASL clinical practice guidelines: management of hepatitis C. Clin Mol Hepatol 2016;22:76-139.

6. Lawitz E, Mangia A, Wyles D, et al. Sofosbuvir for previously untreated chronic hepatitis C infection. N Engl J Med 2013;368:18781887.

7. Gane EJ, Hyland RH, An D, et al. Efficacy of ledipasvir and sofosbuvir, with or without ribavirin, for 12 weeks in patients with HCV genotype 3 or 6 infection. Gastroenterology 2015;149:14541461.e1.

8. Park SH, Park CK, Lee JW, et al. Efficacy and tolerability of peginterferon alpha plus ribavirin in the routine daily treatment of chronic hepatitis C patients in Korea: a multi-center, retrospective observational study. Gut Liver 2012;6:98-106.

9. Lwin AA, Shinji T, Khin M, et al. Hepatitis C virus genotype distribution in Myanmar: predominance of genotype 6 and existence of new genotype 6 subtype. Hepatol Res 2007;37:337-345.

10. Akkarathamrongsin S, Praianantathavorn K, Hacharoen N, et al. Geographic distribution of hepatitis C virus genotype 6 subtypes in Thailand. J Med Virol 2010;82:257-262.

11. Nguyen NH, Vutien P, Trinh HN, et al. Risk factors, genotype 6 prevalence, and clinical characteristics of chronic hepatitis $\mathrm{C}$ in Southeast Asian Americans. Hepatol Int 2010;4:523-529.

12. Pybus OG, Barnes E, Taggart R, et al. Genetic history of hepatitis $C$ virus in East Asia. J Virol 2009;83:1071-1082.

13. Shin SK, Park SY, Jung YK, et al. Prevalence, risk factors and clinical characteristics in patients with genotype 6 chronic hepatitis C: a single institute experience. Korean J Gastroenterol 2015;65:105111

14. Seong MH, Kil H, Kim JY, et al. Clinical and epidemiological characteristics of Korean patients with hepatitis C virus genotype 6 . Clin Mol Hepatol 2013;19:45-50.

15. Oh HB, Kim SO, Cha $\mathrm{CH}$, et al. Identification of hepatitis $\mathrm{C}$ virus genotype 6 in Korean patients by analysis of 5' untranslated region using a matrix assisted laser desorption/ionization time of flight-based assay, restriction fragment mass polymorphism. J Med Virol 2008;80:1712-1719.

16. Thong VD, Akkarathamrongsin S, Poovorawan K, Tangkijvanich P, Poovorawan Y. Hepatitis C virus genotype 6: virology, epidemiology, genetic variation and clinical implication. World J Gastroenterol 2014;20:2927-2940.

17. Tokita H, Okamoto H, Luengrojanakul P, et al. Hepatitis C virus variants from Thailand classifiable into five novel genotypes in 
the sixth (6b), seventh (7c, 7d) and ninth (9b, 9c) major genetic groups. J Gen Virol 1995;76(Pt 9):2329-2335.

18. Kim YJ, Kim SO, Chung HJ, et al. Population genotyping of hepatitis $C$ virus by matrix-assisted laser desorption/ionization timeof-flight mass spectrometry analysis of short DNA fragments. Clin Chem 2005;51:1123-1131.

19. Sohn YH, Ko SY, Kim MH, Oh HB. Performance evaluation of the Abbott RealTime HCV Genotype II for hepatitis C virus genotyping. Clin Chem Lab Med 2010;48:469-474.

20. Yang R, Cong X, Du S, Fei R, Rao H, Wei L. Performance comparison of the versant HCV genotype 2.0 assay (LiPA) and the abbott realtime HCV genotype II assay for detecting hepatitis C virus genotype 6. J Clin Microbiol 2014;52:3685-3692.

21. Cai Q, Zhao Z, Liu Y, Shao X, Gao Z. Comparison of three different HCV genotyping methods: core, NS5B sequence analysis and line probe assay. Int J Mol Med 2013;31:347-352.

22. Wantuck JM, Ahmed A, Nguyen MH. Review article: the epidemiology and therapy of chronic hepatitis C genotypes 4, 5 and 6 . Aliment Pharmacol Ther 2014;39:137-147.

23. Wang X, Liu F, Wei F, Ren H, Hu H. Efficacy and safety of pegylated interferon plus ribavirin therapy for chronic hepatitis $\mathrm{C}$ genotype 6: a meta-analysis. PLoS One 2014;9:e100128.

24. Lam KD, Trinh HN, Do ST, et al. Randomized controlled trial of pegylated interferon-alfa $2 \mathrm{a}$ and ribavirin in treatment-naive chronic hepatitis C genotype 6. Hepatology 2010;52:1573-1580.

25. Thu Thuy PT, Bunchorntavakul C, Tan Dat H, Rajender Reddy K.
A randomized trial of 48 versus 24 weeks of combination pegylated interferon and ribavirin therapy in genotype 6 chronic hepatitis C. J Hepatol 2012;56:1012-1018.

26. Cai Q, Zhang X, Lin C, et al. 24 versus 48 weeks of peginterferon plus ribavirin in hepatitis $C$ virus genotype 6 chronically infected patients with a rapid virological response: a non-inferiority randomized controlled trial. PLoS One 2015;10:e0140853.

27. Nguyen MH, Trinh HN, Garcia R, Nguyen G, Lam KD, Keeffe EB. Higher rate of sustained virologic response in chronic hepatitis $\mathrm{C}$ genotype 6 treated with 48 weeks versus 24 weeks of peginterferon plus ribavirin. Am J Gastroenterol 2008;103:1131-1135.

28. AASLD/IDSA HCV Guidance Panel. Hepatitis C guidance: AASLDIDSA recommendations for testing, managing, and treating adults infected with hepatitis C virus. Hepatology 2015;62:932-954.

29. European Association for Study of Liver. EASL recommendations on treatment of hepatitis C 2015. J Hepatol 2015;63:199-236.

30. Feld JJ, Jacobson IM, Hézode C, et al. Sofosbuvir and velpatasvir for HCV genotype 1, 2, 4, 5, and 6 infection. N Engl J Med 2015;373:2599-2607.

31. Shafran SD. The hepatitis $C$ genotype 1 paradox: cost per treatment is increasing, but cost per cure is decreasing. Can J Gastroenterol Hepatol 2015;29:46-48.

32. San Miguel R, Gimeno-Ballester V, Blázquez A, Mar J. Costeffectiveness analysis of sofosbuvir-based regimens for chronic hepatitis C. Gut 2015;64:1277-1288. 